\title{
De las Ínsulas Del "PeRsiles" A LAS ISLAS INACTUALES DE AZORÍN ${ }^{\mathrm{I}}$ \\ Manuel Calderón Calderón \\ Instituto Español de Lisboa
}

Title: From islands in Persiles to Azorín's nonpresent islands.

\begin{abstract}
Azorín Persiles' reading is closely related to his reflections as a "Minor Philosopher", his historicalliterary essays and his political articles. Three ways to approach his idea of Spain as a nation, which contrasts with the Spain imagined in the Persiles from the same three points of view (metaphysical, moral or customs and political). The disorientation, ambiguities and contradictions with which Azorín and his contemporaries raised this issue still remain today.
\end{abstract}

Key words: The Trials of Persiles and Sigismunda. Utopia. Literature and politics. Azorín.

En su odisea barroca, Periandro y Auristela afrontan una serie de trabajos cuya virtud es la de guiarlos en el descubrimiento de la verdad, que es tanto de orden personal como político. En la Monarquía compuesta de tiempos de Cervantes las ínsulas del Persiles, ajenas al Leviatán en ciernes, constituyen el precedente de las islas pseudoutópicas de Azorín; miembro de una generación que, tres siglos después, apelará a los mitos cervantinos para cartografiar el devenir de los españoles como nación, en un intento de interpretar la tradición, apelando al conocimiento del pasado histórico y de lo que nos une, pero que sigue frustrado por los prejuicios y la insufrible desorientación de quienes prefieren "levantar caramillos en el viento y grandes quimeras de nonada” (Quijote II, 25).

En este sentido, se da en el Persiles un juego dialéctico entre las islas bárbaras y la isla del rey Policarpo; entre la capital de la Cristiandad y la Roma de la justicia venal y la cupiditas (codicia y concupiscencia). Pues tanto para Cervantes como para Azorín (1929: 172), "la verdadera grandeza de un

${ }^{1}$ Una versión reducida de este artículo fue leída el is de noviembre de 2017 en el Congreso Internacional "Cervantes y los mares en los 400 años del Persiles", organizado por el Centro de Humanidades y el Núcleo de Estudos Ibéricos e Ibero-Americanos de la Universidade Nova de Lisboa. 
país reside en su atmósfera moral, en las nociones de humanidad que el tipo medio de una nación tenga". Es el mismo ethos (mos, moris) que viajó desde la Grecia de Heródoto hasta la América de Tocqueville y de Domingo Faustino Sarmiento (2002: 474-475).

Por otro lado, el adjetivo bárbaros tiene tres significados en el Persiles: a) extranjeros (septentrionales); b) expatriados del sur de Europa (el español Antonio, el sienés Rutilio); y c) quienes no practican la moral cristiana, como "los bárbaros salvajes" que prefieren ser justicieros a misericordiosos y la "bárbara egipcia” Rosamunda (en alusión a la mujer de Putifar, del Gn. 39). Las tres acepciones de la palabra bárbaro se refieren a quienes están fuera de su centro geográfico, cultural, político y moral, que Cervantes sitúa en el Mediterráneo y que para Azorín está en las grandes ciudades como París. Son estos núcleos de población los que, según el autor de La isla sin aurora, producen lo que él llama la "densidad" histórica (Azorín, r 9r4) y las “condensaciones" culturales, es decir, las elaboraciones que el novelista hace de lo real después de haberlo pasado por el inconsciente (Azorín, I 929: I79). De ahí mi referencia en el título de esta exposición al Caballero inactual, Félix Vargas ( 1928a), quien en la época de Mme. de Staël y Benjamin Constant, se pasa la novela tratando de llevar a Santa Teresa al Mediterráneo.

Estética, metafísica y política, como propugna Azorín (1944b: 199203 y 233-235; 1945: 136), van también de la mano en el Persiles, a través de la varietas con que Cervantes combina pintura, música y literatura en su narración; intercalando distintos géneros literarios (lírica, teatro, novela), sobre los que unas veces ironiza y que otras le sirven para reflexionar acerca de "la inconstancia de nuestras vidas y la del mar" (Cervantes, i 969: 253). Periandro, los bárbaros Antonio (padre e hijo) y el desterrado Renato son, además, "extraños y forasteros sobre la tierra, en busca de una patria"

${ }^{2}$ Miguel de Cervantes, Los trabajos de Persiles y Sigismunda, ed. de Juan Bautista AvalleArce, Madrid: Castalia, 1969, pp. 94, 142, 233, 31 8, 325-326. 
(Hebreos I I: I3-ı6); como aquella que el sienés Rutilio sin duda había visto pintada por Ambrogio y Pietro Lorenzetti en el palacio comunal de su ciudad.

En las Cortes de la Restauración, también eran “inaceptables” para Azorín ( 19 14: 77 y I 25- - 26) "la barbarie, la crueldad, la grosería o, simplemente, la incorrección”. Por eso añade que "no puede darse un ideal ético que no determine un sistema político” (Azorín, i 944b: 199). Pues desde su punto de vista, que es el de Platón y Cervantes en el libro tercero del Persiles, la vida, el mundo y el arte conforman algo que "es sin acabar de ser nunca”. O como dice el narrador-traductor del Persiles: "todos deseaban, pero a ninguno se le cumplían sus deseos; [...] la cual falta siempre la ha de haber mientras no dejáremos de desear" (Cervantes, i 969: 176).

El eje sobre el que gira el tema político en el Persiles es aquella aludida noción de humanidad, opuesta a la barbarie; noción que no es gratuita ni está garantizada para siempre. Por el contrario, exige de nosotros una tensión permanente para apropiárnosla y transmitirla en cada generación. Veamos.

El rey de la Isla Escinta, Policarpo, es un rey absoluto y vitalicio, pero sólo mientras sea virtuoso en sentido cristiano, no en sentido pagano y maquiavélico. Dicho sistema político garantiza la paz, la justicia y la misericordia, "sin temor de los insolentes", así como que "cada uno pueda gozar lo que es suyo" (Cervantes, I 969: I 50). La estancia en aquella isla aviva el optimismo de la enferma Auristela. Allí también gana Periandro varias medallas en unos juegos olímpicos. Pero entre los dos primeros libros del Persiles y los dos siguientes, así como en la isla de Policarpo, hay una serie de tensiones entre:

I) Occidente y Oriente.- La obsesión de Cervantes - dice Azorín- era la luz, el Mediterráneo. A la tradición helénica se añade en el Persiles, como en las escalas de Levante de El amante liberal, "una lucha viva y tenacísima entre dos civilizaciones" 
(Azorín, I92 I: 202-203). El polaco Ortel Banedre se embarca en Lisboa hacia las Indias orientales y, después de quince años, conoce en un mesón de Talavera a una "moza que es más del suelo que del cielo”, como dirá Soldino (Cervantes, i 969: 397). En lo cual apunta una segunda tensión entre

2) Moral católica e instinto.- El propio rey Policarpo es un septuagenario que da en la flor de enamorarse de una adolescente, tópico que Cervantes ya ha tratado en otra novela y en un entremés. En el Persiles lo hace dentro de la ortodoxia católica; punto de vista desde el cual tanto Policarpo como Rosamunda, creadora de una moral propia, han de fracasar por fuerza.

A pesar de ello, el tema amoroso está planteado en un sentido ejemplar (no moralista, sino dialéctico), con sus pares de opuestos: amor-matrimonio, amor-interés, amor por destinoamor por elección, honestidad-lascivia, confianza-celos, amor generoso-amor vengativo, amor antojadizo (por la belleza)-amor del alma. Lo que nos lleva a una tercera dicotomía entre

3) Orden y caos.- Policarpo "no sabe lo que le pasa" y "nadie en su corte pone cuidado en nada”, observa Azorín (igr s: 225). Como en la España de su época y también en la de hoy, donde "nadie está en su sitio, en el momento exacto y cumpliendo escrupulosamente con el deber", sin "trámites, aplazamientos, equívocos, laxitud, compadrazgo, miedo"; donde "los ideales no tienen su encarnación en la realidad"; y donde los políticos no "fabrican densidad", pues en lugar de continuar "una civilización que para formarse ha necesitado una larga y fecunda tradición", han abdicado de ella. El resultado es la "incoherencia" que resulta de carecer de una idea común de España y de anteponer los intereses del partido a los de la nación (Azorín, I 9I 4: I I 9-I 27 y I65). ${ }^{3}$

${ }^{3}$ Azorín distingue entre la "nación española" y el "Estado español", que "lo constituyen los políticos" (Azorín, 1923: 399): tanto aquellos que aprobaron la Mancomunidad catalana, dos meses antes del discurso de La Cierva y tres años antes de la Huelga General 
4) Deseos y destino.- A Azorín le inquieta "el destino oscuro y trágico, mezclado con cosas grotescas” de los peregrinos que acompañan a Periandro y Auristela, "impulsados por una fuerza que ellos mismos desconocen” (Azorín, i915: 22 I y 225). En efecto, todos marchan hacia lo ignoto, no ya en busca de aventuras, como los caballeros andantes, sino impulsados por la Providencia.

5) Mundo externo e interno.- Pero aunque el Persiles parta de una cosmovisión católica, su autor no se limita al mundo interior del espíritu, sino que hace constantes alusiones a la vida activa. Periandro arenga así a los pescadores:

La baja fortuna jamás se enmendó con la ociosidad ni con la pereza [...] nosotros mismos nos fabricamos nuestra ventura [...] Llamo generoso al trabajo del que se ocupa en cosas grandes. [...] Hagámonos piratas, no codiciosos como son los demás, sino justicieros como lo seremos nosotros. (Cervantes, I 969: 224-225).

El tema del autoconocimiento, tan importante en el Persiles, forma parte también de La isla sin aurora, novela de Azorín donde el agua (que refleja lo que pasa en el espacio), la nube (que refleja lo que transcurre en el tiempo) y la luz (que " $\mathrm{da}$ colores a las sombras a ciertas horas”) provocan las meditaciones del poeta sobre la realidad externa (que es la apariencia) e interna ("la profundidad del misterio") (Azorín, I 944a: I Io- I I I). ${ }^{4}$

Esta nueva tensión o dicotomía, trasladada al terreno político, se plantea en el Persiles entre la isla del cuerpo (la del rey Policarpo) y la isla del espíritu o de las Ermitas. En este sentido, más que la ciencia y la técnica que domestican la Naturaleza y

Revolucionaria, convocada en Barcelona coincidiendo con la Asamblea de Parlamentarios, como los que han creado nuestro actual Estado de Partidos, dedicado a inventar naciones mediante el ariete de la política lingüística.

${ }^{4}$ Nótese el paralelismo con la luz que envuelve las dos peregrinaciones del Persiles: la septentrional y marítima de los dos primeros libros y la meridional y terrestre de los dos siguientes. 
facilitan y aseguran la vida, el fauno viejo de La isla sin aurora prefiere la $\mathrm{Fe}$ (que nos impide entregarnos a la desesperación, otro tema del Persiles), así como la Esperanza y la Caridad, que no son producto de la Naturaleza, sino de la vida social. Lo que nos lleva a una postrera tensión entre

6) Voluntad de poder y tolerancia.- Es la misma dicotomía amor-odio personificada por el desprendido y curioso Periandro y por el mundano y rencoroso Clodio, respectivamente. $\mathrm{Y}$ sin embargo, el amor en el Persiles sirve también para canalizar la ambición de poder, cuya disputa desemboca en una guerra civil entre los partidarios de Bradamiro y del gobernador o capitán de la ínsula bárbara (Persiles I, 4). ${ }^{5}$

Todas estas tensiones explican por qué el Persiles no llega a ser una utopía; es decir, un fin de la historia hegeliano. En segundo lugar, Cervantes siempre añade, junto al punto de vista ideal (lo que debe ser), el de la experiencia (lo que es):

A Periandro "le parecía que tal vez las leyes del gusto humano tienen más fuerza que las de la religión"; "como cristiano que soy católico no lo creo; pero la esperiencia me muestra lo contrario" - dice Rutilio (Cervantes, I969: 92). "Segú las costumbres de mi patria, a lo menos en cuanto a las que parecían ser niveladas con la razón, y en las que no, con apariencias fingidas mostraba seguirlas, que tal vez la disimulación es provechosa"- añade Mauricio, un astrólogo judiciario igualmente pragmático. (Cervantes, I969: I I I).

En tercer lugar, el Persiles narra los trabajos (lucha, agonía) de sus protagonistas, identificados con la misma escritura de la novela - "mis trabajos y los de mi hermano nos van leyendo en cuánto debemos estimar el

${ }^{5}$ En La isla sin aurora (Azorín, I 944a: 6 I-62), en cambio, es Manuel de Rodríguez (nombre que coincide con el de una isla chilena del Estrecho de Magallanes) quien opone la necesidad de negociaciones y acuerdos al ejercicio excluyente del poder: "ceder para que la convivencia sea posible"; tema que Azorín desarrolla en otros lugares: De Granada a Castelar (1922), El Chirrión de los políticos (1923) y al final de Una hora de España (1924). 
sosiego", dice Auristela (Cervantes, 1969: 187)-; que si, por un lado, son imitación de los de Cristo - “desde que se mostró en el pesebre hasta que se puso en la cruz" (Cervantes, i 969: 436) -, por otro resultan inestables y efímeros.

"La hermosa junta peregrina” del Persiles atraviesa así un círculo ideal que va desde su arco (la Isla de Tule y la Isla Bárbara o de los cautivos) hasta su centro (Roma), la ciudad santa que, al mismo tiempo, es la Síbaris o Babilonia de las cortesanas, de la injusticia y la mutación, es decir, la muerte. A lo largo de esta peregrinación, sus héroes van superando las utopías del buen salvaje (la Isla Bárbara), la del Estado racional (la isla del rey Policarpo, un rey vagamundo como Lear), la de la vida retirada (la Isla de las Ermitas) y finalmente, la del Estado aristotélico-tomista y del Imperio universal, disuelta por el empirismo maquiavélico y el Leviatán barroco.

Dos siglos más tarde, en el contexto de la expansión colonial europea en África, la crisis política de la Restauración canovista y el debate sobre la regeneración nacional, Ángel Ganivet y Pío Baroja escribieron sendas utopías satíricas: La conquista del reino de Maya (1895) y Paradox, rey (1906), a las que siguieron las utopías socialistas de Luis Araquistáin, El archipiélago maravilloso (1923) y de su correligionario, el opulento bilbaíno embarcado en el Indalecio Prieto, quien naufraga en la isla de la Serenidad (1 925 ); ínsula antiutópica con que Azorín nos recuerda que una partidocracia no es una democracia ni la política un juego de aprendices de brujo. ${ }^{6}$

${ }^{6}$ La partidocracia o vigente Estado de Partidos, ideado por Gerhard Leibholz después de la SGM, pretende superar al Estado de Derecho (el Derecho es previo al Estado) y al Gobierno bajo el imperio de la ley (la jurisprudencia es lo que crea el Derecho y los partidos políticos son parte de la sociedad, nunca del Estado). Por el contrario, en la partidocracia es el Estado quien crea el Derecho, financia a los partidos políticos, que son parte del Estado e introducen la ideología de partido en el Estado, generando leyes moralizantes que invaden el espacio privado de las personas. Dicho modelo es el que sigue el actual Régimen constitucional español. 
En cuanto a la otra isla antiutópica de Azorín (1944a), carece de aurora por dos motivos:

Primero porque la transición que sugiere la aurora entre la luz y las tinieblas (o entre un mundo superior y un mundo inferior, que es como aún divide Goethe el mundo en su Diván de Oriente y Occidente) pierde vigencia después de la nietzscheana segunda muerte de Dios.

Y sobre todo, porque - como afirma Lord Macduff en el Macbeth IV, 3-“en cada nueva aurora gimen nuevas viudas, gritan nuevos huérfanos”. Pues a diferencia del cervantino Clodio, quien sí tiene planes y teorías definitivas para el futuro -como el mejor astrólogo del mundo, que es el demonio (Cervantes, I 969: I 16)-, en La isla sin aurora la amenaza de un reposo inerte - la paz universal, la edad de la Razón o el fin de la historia-, es decir, de "este no esperar ya nada, comenzaba a poner cierta desazón en sus habitantes", porque "no importa lo que en la vida se espere; lo fundamental es esperar algo" que no haya sido programado por otros (Azorín, i 44a: i i 4).

A pesar de todo, Cervantes es el escritor alegre, como Periandro; seguidores en esto del apóstol (Filipenses 4: 4). Y lo es en tres sentidos, nada vigentes en la España actual:

a) Frente a los escritores tristes o postmodernos, seguidores de lo que Paul Ricoeur llamó 'los filósofos de la sospecha', cuyo precedente en el Persiles es el detractor Clodio; es decir, aquellos anatomistas u "hombres tristes que son especialistas magistrales en hacer autopsias de situaciones y de vidas, de las contradicciones de la realidad" con "cuchillas que se afanan sobre el mundo para diseccionarlo y arrastrarlo luego, aniquilarlo" (Jiménez Lozano, 200o : 82-83). Los mismos que Matías Belarte encarna en la novela de Álvaro Pombo, Quédate con nosotros, Señor, porque atardece (2O I 3). Por el contrario, hemos visto que 
Persiles no quiere ser un pirata como Dragut y Alí Pachá; tampoco como Nietzsche, sino como

los navegantes del espíritu que lo han precedido, heroicos y audaces, que habían descubierto imperios y continentes como conquista para la civilización y para la humanidad, a fin de completar también el mapa geográfico de la filosofía y conocer, cada vez más, la porción de terra incognita del pensamiento. Ellos plantan su bandera de Dios o del espíritu en la nuevas tierras que conquista; edifican ciudades, templos, calles en esas regiones antes desconocidas, y tras ellos llegan los gobernantes o los administradores para cultivar los nuevos campos y recoger sus cosechas, es decir, llegan los comentadores, los profesores, los hombres de cultura. El sentido último de sus trabajos era el descanso, la paz, la seguridad; quieren aumentar las posesiones del mundo, propagar las normas y las leyes, todo lo que es orden superior. Nietzsche, al contrario, entra en la filosofía alemana como entraron en el Imperio español los filibusteros del final del siglo XVI, un enjambre de desesperados sin patria, sin amor, sin rey, sin bandera y sin hogar (Zweig, I 999: 270-27I).

b) Porque Cervantes no concibe la violencia y el odio, con que rima Clodio (Baena, I 988: 139), como medios para ejercer la política. Ese odio que crea víctimas, fronteras, fingidos agravios e identidades excluyentes.

c) Y porque las palabras no están, para el narrador del Persiles, al servicio de la política, como sostendrán Mefistófeles (Fausto, vv. 1993-2000) y un reciente y ominoso Presidente del Gobierno de España, de cuyo nombre no quiero acordarme. En cambio, el astuto Clodio sabe que aunque todo bellaco y traidor enfaden, su agudeza contenta y sirve para atraer voluntades. Por eso él se deleita con la maledicencia — “el gusto que recibo de decir mal cuando lo digo bien" (Cervantes, I969: I I9)- que antepone a la clemencia, como le reprocha Rosamunda.

Por otro lado, Azorín atribuye a Cervantes uno de los estribillos de su generación ${ }^{7}$ y, luego, de la de Ortega: la identificación de racionalidad con

${ }^{7} \mathrm{La}$ de los intelectuales de la Revista Nueva (I 899), el 'manifiesto de los tres' (firmado por Pío Baroja, Azorín y Ramiro de Maeztu en diciembre de I90 I), la revista Juventud y el 
europeísmo, exhortando a "apropiarnos, en arte y en política, la sustancia universal" humana y una supuesta "conciencia europea"; aunque -añade Azorín (I 929: I 80) - “sin dejar de ser de la nación”.

Ahora bien, cuando salimos al paso de "la peregrina escuadra" del Persiles, ¿qué nos encontramos? La nave que aprovisiona periódicamente a Renato en la Isla de las Ermitas le trae nuevas de Europa, sí; pero la Europa de Cervantes es

I. la de los bárbaros, en cualquiera de las tres acepciones que hemos visto;

2. la Europa de Carlos V, "asombro de los secuaces de Mahoma” (Cervantes, 1969: 273);

3. una Europa donde España es "madre común de las naciones”, según el polaco Ortel Banedre (Cervantes, i 969: 3 16);

4. y una Europa cuya mayor ciudad es Lisboa, metrópoli con ricos templos, católicas ceremonias y caridad cristiana (Cervantes, I 969: 277).

O sea, la actualización de un mito; pues así como en "Francia ni varón ni mujer deja de aprender la lengua castellana” — constata el narradortraductor del Persiles-, la princesa fenicia raptada por Zeus es, a la sazón, una dama francesa raptada por el hijo de "un gallardo español” (Cervantes, I 969: 368 y 380$) .8$

Por tanto, nada de lo anterior tiene que ver con lo que Azorín (i 9 i s: 2 I 7 y 232) entiende por Europa y atribuye a Cervantes ("lo definido, lo claro, lo lógico, lo coherente, el cosmopolitismo”). Azorín asume la teoría

semanario regeneracionista La República de las Letras (1905), donde Pérez Galdós reivindica unas humanidades que salgan de las capillitas y cenáculos eruditos para interesar tanto a los que saben leer y no leen como a los que leen y no entienden.

${ }^{8}$ Feliz Flora es una sinécdoque de Francia, país que para Azorín y su generación era, a su vez, una sinécdoque de Europa: Al margen de los clásicos (I 9 I 5); Un pueblecito: Ríofrío de Ávila (1916); Los dos Luises (192 I); De Granada a Castelar (1922). 
intelectualista de Larra sobre el tópico de la decadencia histórica de España, pero con precisiones y rectificaciones, pues reconoce que "un hombre que puesto el pensamiento en su patria, haga referencia a un pasado esplendoroso de su patria como un ideal deseable, no será un espíritu moderno y progresivo" (Azorín i 914: 82).

Con todo, en plena Grande Guerre, Europa es para Azorín (i9i6: 542) "la máquina y la ideología"; nos exhorta a "seguir todo aquel movimiento intelectual y científico para integrarlo en nuestro ambiente", al tiempo que se percata de que "los Estados Unidos, de potencia exclusivamente americana se había convertido en Estado mundial” y de que "no se habría decidido a intervenir en la guerra si no contara, tras la victoria, con imponer su ideal en el mundo". Un ideal basado en la utopía kantiana más lo que Azorín llama unificación de las comunicaciones, la moneda, los mercados, la industria, las finanzas y los ejércitos; Aldous Huxley, Estado Mundial y hoy llamamos globalización. ${ }^{9}$

Desde otro punto de vista, Ernst Jünger ha sintetizado estas transformaciones en cinco figuras simbólicas del siglo XX: el Bosque, un lugar interior opuesto a la Nave o el Leviatán; el Soldado desconocido y el Trabajador. De estos tres últimos trata de salvaguardarse el Emboscado. "El Trabajador es el principio activo que se despliega en la tentativa de imponerse al universo y dominarlo"; mientras que el Emboscado, como Persiles, "es el privado de patria, pero que ofrece resistencia"; "tiene una relación originaria con la libertad, se opone al automatismo y piensa no sacar la consecuencia

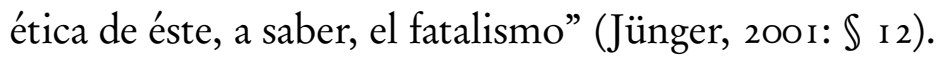

${ }^{9}$ Huxley (20 I0: I 9); Azorín (I 9 I 8: I I O4- I IO5 y i I I 2-I I I 3), quien parodia los mecanismos de este mundo feliz en el capítulo XXI de El caballero inactual (i $928 \mathrm{a}$ ); mundo sobre el cual un descendiente de Cipión y Berganza nos da su opinión, en el capítulo XXXVI de Pueblo (1930). Sin embargo, Azorín no vislumbró, como Huxley y Orwell, la sustitución forzada pero taimada y paulatina - que no de un plumazo, como en el capítulo tres de la novela de Huxley- de ideas, valores y creencias mediante leyes de normalización e ingeniería social. 
¿Qué papel juega el poeta de La isla sin aurora en esta civilización automatizada, funcional y fundada en la productividad económica y en la técnica? Sólo sabemos que el capitán Pasquier y el Poeta son incompatibles porque éste bebe ginebra Estrella (antes de ver la manzana de oro, contempla desde la azotea las estrellas) y aquél bebe ginebra Llave ("Llave" se titula un capítulo de Pueblo, sobre la agonía de un labriego que tiene una llave pequeña y tosca para abrir el cajón del pan; cuando muere, ya no hay llave ni pan para la mujer y los niños. Y otro poeta, el inactual Félix Vargas, pierde su manojo de llaves).

Uno de los símbolos más caro a Azorín, a este respecto, es el de la araña. Encarece su vitalidad, su adaptación al medio (acuático, terrestre y aéreo), su rápida y vigorosa disposición para la lucha; pero a diferencia de la avispa, es solitaria e independiente (Azorín, I 920: I 27). ${ }^{\text {Io }}$ Le llama la atención, además, que Cervantes diga en el Persiles que en Inglaterra no hay arañas; porque Azorín se imagina a la sociedad como un inmenso telar con los "hilillos de la ilusión del pueblo, de las muchedumbres que trabajan y sufren [...] En tanto, por debajo de esta urdimbre, se han ido formando nudos que son bancos, sociedades industriales, empresas, consorcios, monopolios. Una red que cubre y aprisiona el planeta” (Azorín, i 930: cap. XLVI).

Mientras que el ideal de vida en el Persiles es el sosiego, que no excluye la pasión de la infinitud (Kierkegaard), frente a la apatía estoica - la que abona, en cambio, el huerto de Cándido- y frente a la ataraxia de algunos personajes azorinianos.

En una ocasión, Azorín (1925) imagina el encuentro entre el buen rey Nicéforo I de Farsalia, protagonista de la novela homónima de José María Salaverría (i919), y el Segismundo de La vida es sueño, reconvertido en

${ }^{10}$ Encontramos más referencias a las arañas en Azorín (1 923: 393-394; 1 928 b: la arañita en el espejo; I944b: I37-1 38 y i 945: 690). Marc Fumaroli ha estudiado la querella entre antiguos y modernos en un libro titulado Las abejas y las arañas, trad. de Caridad Martínez, El Acantilado: Barcelona, 2008. 
activista utópico. En otra ocasión, imagina al mismo Segismundo despertando en la corte, después de apurar el bebedizo; pero sin alegría por su nuevo estatus ni rencor por haber sido privado de él; simplemente, se hace el dormido porque no quiere saber nada del Gobierno. Al igual que Persiles, este nuevo avatar de Segismundo "emprendió largos viajes. En un ligero barco, con un centenar de libros, salió un día de Kolberg, en Alemania, para los mares del Norte. Y no se le ha vuelto a ver más”, como al histórico Juan Salvador de Habsburgo-Lorena, amigo del único hijo del emperador Francisco José e Isabel de Baviera (la famosa Sissí), con quien compartía ideas liberales en asuntos de Gobierno (Azorín, I 940: 957-96 I).

Son las tres principales formas de hacer política en el reinado de Alfonso XIII: el liberalismo, el anarquismo y el socialismo. Azorín (I 9 I 4: I 4OI 4 I) apenas hace una vaga alusión a los nacionalismos. Sin embargo, después de la Guerra de Restauración portuguesa (I640-I668), hubo una refeudalización de la Monarquía hispánica que ha sobrevivido a las diferentes formas de Estado y de Gobierno para recidivar en el actual Régimen constitucional, cuyas secuelas de desigualdad laboral, fiscal y educativa, odio inculcado en las aulas y en los medios de comunicación, enfrentamiento institucional, inseguridad jurídica e inestabilidad política han aumentado paulatinamente en las últimas cuatro décadas. ${ }^{\mathrm{I}}$

En una novela publicada en España en los albores de la Transición $(\text { I } 975 \text {-1982 })^{12}$ y que fue premio Planeta, el narrador recuerda que a la última guerra civil "la llamábamos "guerra de liberación”. España, al fin, era autó-

${ }^{1}$ La sesión parlamentaria que Azorín describe en el capítulo nueve de El chirrión de los políticos (1923) esconde los privilegios mollares de las oligarquías nacionalistas, precedente de las que han creado el actual Estado de las Autonomías, cuyos delirantes derechos históricos son un atavismo anterior a la soberanía nacional, al sufragio universal y a la igualdad de todos los españoles.

${ }^{12}$ Así se ha llamado en España al paso de las leyes de un Régimen autoritario a las leyes de un Régimen constitucional; el cual, asombrosamente, dispensa de su cumplimiento a los gobiernos nacionalistas de ciertas autonomías. 
noma, sin interferencias extranjeras, una isla en Europa." (Salisachs, 200 I: 2 I6-2 I7) Por el contrario, durante la Transición se optó por convertir esta isla en un archipiélago de comunidades autónomas, integradas en un continente llamado Unión Europea, inscrito a su vez en un mundo ashavérico o globalizado.

Si miramos al otro lado del Atlántico, Pero Vaz de Caminha creyó que la tierra recién descubierta por Cabral era una isla y la llamó Ilha da Vera Cruz. De este equívoco nació el mito fundador de la Ilha-Brasil. A su vez, para Érico Veríssimo, en O Tempo e o Vento (I 949-1 96 I), “cada homem é uma ilha com seu clima, sua fauna, sua flora e sua história" que siente la nostalgia de un Continente "batido pelo vento e pelo tempo" y que puede ser cualquier cosa: Dios, el socialismo, el Rotary Club o la Raya Blanca da la Umbanda (Calderón, 200I: 222).

En cuanto a los españoles de hoy, "como están nuestras almas siempre en continuo movimiento" (Cervantes, 1969: 275), seguimos mareando por islas utópicas, archipiélagos 'asimétricos' (variante socialista de las autonomías) y otros avatares de la ilha perdida (denominación del Infierno, en las Barcas de Gil Vicente), en una cansina actualización de Los trabajos de Persiles y Sigismunda.

\section{BibliografíA}

Azorín [José Martínez Ruiz] (1914), Un discurso de La Cierva, en Obras completas, intr., notas preliminares, bibliografía y ordenación por Ángel Cruz Rueda, Madrid: Aguilar, vol. III, pp. 63-I69.

Azorín [José Martínez Ruiz] (i 9 I s), Al margen de los clásicos, en Obras completas, vol. III, pp. 217-235.

Azorín [José Martínez Ruiz] (i 916), Un pueblecito: Riofrío de Ávila, en Obras completas, vol. III, pp. 527-595.

Azorín [José Martínez Ruiz] (i9i8), Los norteamericanos, en Obras completas, vol. III, pp. IO69-I I I 4.

Azorín [José Martínez Ruiz] (I92 I), Los dos luises y otros ensayos, en Obras completas, vol. IV, pp. $14 \mathrm{O}-2 \mathrm{I} 3$.

Azorín [José Martínez Ruiz] (1922), De Granada a Castelar, en Obras completas, vol. IV, pp. 277-388.

Azorín [José Martínez Ruiz] (1923), El chirrión de los políticos (fantasía moral), en Obras completas, vol. IV, pp. 389-486. 
Azorín [José Martínez Ruiz] (i 924), Una hora de España (entre i s6oy I 590), en Obras completas, vol. IV, pp. 487-578.

Azorín [José MarTínez Ruiz] (1925), Los Quinteros y otras páginas, en Obras completas, vol. IV, pp. 619-733.

Azorín [José Martínez Ruiz] (i928a), El caballero inactual (etopeya) [Félix Vargas], en Obras completas, vol. V, pp. 29- I09.

Azorín [José Martínez Ruiz] (1928b), Lo invisible, en Obras completas, vol. IV, pp. IO29- IO7 I.

Azorín [José Martínez Ruiz] (1929), Andando y pensando (notas de un transeúnte), en Obras completas, vol. V, pp. i I I-222.

Azorín [José Martínez Ruiz] (i 930), Pueblo (novela de los que trabajan y sufren), en Obras completas, vol. V, pp. 5 I I-594.

Azorín [José Martínez Ruiz] (1940), Pensando en España, en Obras completas, vol. V, pp. 9i IIO84.

Azorín [José Martínez Ruiz] (I 944a), La isla sin aurora, en Obras completas, vol. VII, pp. 29- I 28.

Azorín [José Martínez Ruiz] (i $944 b)$, Tiempos y cosas, en Obras completas, vol. VII, pp. I 29-262.

Azorín [José Martínez Ruiz] (1945), Leyendo a los poetas, en Obras completas, vol. VII, pp. $678-818$.

Baena, Julio (1988), "Los trabajos de Persiles y Sigismunda: La utopía del novelista", Cervantes: Bulletin of the Cervantes Society of America, VIII, 2, Fall i 988, pp. I 27-I 40.

Calderón Calderón, Manuel (200I), "Essa castelhanada do resto de América: señas de identidad y fronteras culturales en O tempo e o vento", Anuario Brasileño de Estudios Hispánicos, XI, pp. 207-225.

Cervantes, Miguel de (1969), Los trabajos de Persiles y Sigismunda, ed. de Juan Bautista Avalle-Arce, Madrid: Castalia.

Huxley, Aldous (2010), Un mundo feliz, trad. de Ramón Hernández, Barcelona: Debolsillo.

JimÉnez Lozano, José (2000), Un hombre en la raya, Barcelona: Seix Barral.

JünGER, Ernst (2O I I), La emboscadura, Barcelona: Tusquets.

Salisachs, Mercedes (200I), La gangrena, Barcelona: Planeta.

Sarmiento, Domingo Faustino (2002), Viajes por Europa, África y América, en Obras selectas, ed. de Diana Sorensen, Madrid: Espasa-Calpe, pp. 325-519.

Zweig, Stefan (1999), La lucha contra el demonio, trad. de Joaquín Verdaguer, Barcelona: El Acantilado.

recibido: abril de 2018 aceptado: mayo de 2018 
